OPEN ACCESS

Edited by:

Zhanglin Lin,

South China University of Technology,

China

Reviewed by:

Zhaoyong Yang,

Chinese Academy of Medical

Sciences, China

Xueli Zhang,

Tianjin Institute of Industrial

Biotechnology (CAS), China

Marc Tancredi Facciotti,

University of California Davis, USA

${ }^{*}$ Correspondence:

Martin Hernán Bonamino

mbonamino@inca.gov.br

tThese authors have contributed equally to this work.

Specialty section:

This article was submitted to

Synthetic Biology,

a section of the journal

Frontiers in Bioengineering and

Biotechnology

Received: 04 September 2016

Accepted: 20 December 2016

Published: 23 January 2017

Citation:

Chicaybam L, Barcelos C, Peixoto B, Carneiro M, Limia CG, Redondo P,

Lira C, Paraguassú-Braga F, Vasconcelos ZFMD, Barros $L$ and Bonamino MH (2017) An Efficient Electroporation Protocol for the Genetic Modification of Mammalian Cells.

Front. Bioeng. Biotechnol. 4:99. doi: 10.3389/fbioe.2016.00099

\section{An Efficient Electroporation Protocol for the Genetic Modification of Mammalian Cells}

\author{
Leonardo Chicaybam ${ }^{1,2 t}$, Camila Barcelos ${ }^{1 \dagger}$, Barbara Peixoto', Mayra Carneiro', \\ Cintia Gomez Limia', Patrícia Redondo ${ }^{3,4}$, Carla Lira ${ }^{5,6}$, Flávio Paraguassú-Braga $^{5}$, \\ Zilton Farias Meira De Vasconcelos ${ }^{6}$, Luciana Barros ${ }^{1}$ and Martin Hernán Bonamino ${ }^{1,2 *}$
}

${ }^{1}$ Programa de Carcinogênese Molecular, Coordenação de Pesquisa, Instituto Nacional de Câncer (INCA), Rio de Janeiro, Brazil, ${ }^{2}$ Fundação Instituto Oswaldo Cruz, Vice-presidência de Pesquisa e Laboratórios de Referência, Rio de Janeiro, Brazil, ${ }^{3}$ Instituto de Ciências Biomédicas, Universidade Federal do Rio de Janeiro, Rio de Janeiro, Brazil, ${ }^{4}$ Centro de Transplante de Medula Óssea, Instituto Nacional de Câncer, Rio de Janeiro, Brazil, ${ }^{5}$ Banco de Cordão Umbilical e Placentário, Instituto Nacional de Cancer (INCA), Rio de Janeiro, Brazil, ${ }^{6}$ Instituto Fernandes Figueira, Fundação Oswaldo Cruz, Rio de Janeiro, Brazil

Genetic modification of cell lines and primary cells is an expensive and cumbersome approach, often involving the use of viral vectors. Electroporation using square-wave generating devices, like Lonza's Nucleofector, is a widely used option, but the costs associated with the acquisition of electroporation kits and the transient transgene expression might hamper the utility of this methodology. In the present work, we show that our in-house developed buffers, termed Chicabuffers, can be efficiently used to electroporate cell lines and primary cells from murine and human origin. Using the Nucleofector II device, we electroporated 14 different cell lines and also primary cells, like mesenchymal stem cells and cord blood CD34+, providing optimized protocols for each of them. Moreover, when combined with sleeping beauty-based transposon system, long-term transgene expression could be achieved in all types of cells tested. Transgene expression was stable and did not interfere with CD34+ differentiation to committed progenitors. We also show that these buffers can be used in CRISPR-mediated editing of PDCD1 gene locus in 293T and human peripheral blood mononuclear cells. The optimized protocols reported in this study provide a suitable and cost-effective platform for the genetic modification of cells, facilitating the widespread adoption of this technology.

Keywords: electroporation, cell line, MSC, T lymphocyte, CD34, transposon, CRISPR, PD-1, GFP

\section{INTRODUCTION}

Cell lines are valuable tools for research development, constituting one of the pillars of experimental biology. Their unlimited proliferative capacity, high degree of homogeneity, and relatively easy maintenance in culture allow the generation of large number of cells required for testing

\footnotetext{
Abbreviations: CRISPR, clustered regularly interspaced short palindromic repeats; TALEN, transcription activator-like effector nucleases; PBMCs, peripheral blood mononuclear cells; MSCs, mesenchymal stem cells; GFP, green fluorescent protein; RFP, red fluorescent protein; 7-AAD, 7-amoniactinomycin D; ITR, inverted terminal repeats; SB, sleeping beauty transposase; dpi, days post inoculation; gRNA, guide RNA; NHEJ, non-homologous end joining; FITC, fluorescein isothiocyanate; HSC, human stem cell.
} 
numerous candidate drugs (Barretina et al., 2012), -omics profiling (Nishizuka et al., 2003; Griffin and Shockcor, 2004; Blower et al., 2007), and signaling pathways studies (Park et al., 2010), to cite some examples. One of the areas that benefited the most with the use of cell lines was cancer research, with the derivation of several cell lines that can be used as models for different cancers. These cells are used to model disease in vitro and in vivo, providing information about oncogenesis-related pathways and insights into therapeutic strategies (Gillet et al., 2013). Moreover, cell lines are central players in the biotechnology industry, being used in the production of biopharmaceuticals like antibodies, hormones, and bioactive proteins in general (Kuystermans and Al-Rubeai, 2015).

The use of cell lines in basic research is often associated with genetic modification protocols, which allow overexpression and/or silencing of desired genes in a controllable fashion. Recently, the development of gene editing tools like TALENs and CRISPRs provided a more precise control of gene insertion or deletion, extending the possible genomic manipulations (Kim and Kim, 2014). Methods to deliver foreign genetic material (DNA or RNA) usually rely in nonviral or viral vectors, with the former being preferred because of increased biosafety, easier production, and faster translation. Electroporation is a nonviral method for gene transfer that is demonstrating encouraging results, being successfully used for the manufacture of antitumor lymphocytes (Ramanayake et al., 2015) and other applications (Kotnik et al., 2015), but the mechanism of DNA/RNA transfer is not fully understood (Satkauskas et al., 2012). Moreover, the use of electroporation is associated with extensive testing of electric parameters (pulse amplitude, volts) in order to optimize the protocol. Nonviral methods like liposomes and electroporation show varying efficiencies, with several cell lines and primary cells showing poor transfection rates and cell death (Wang et al., 2012; Yin et al., 2014). In the case of liposomes, the transfection of non-adherent cell lines is rather inefficient, showing good results only for some adherent cells (Jordan and Wurm, 2004; Behr, 2012).

Using a square-wave pulse technology, Lonza's Nucleofector electroporator was shown to be very efficient in several cell lines and primary human and murine cells, inducing high expression of the transgene and substantial viability. The pre-loaded electroporation programs suited for each cell line simplify the experimental setup, and the use of proprietary additives improves the transfection efficiency. However, the frequent use of Nucleofector electroporation kits implies in important costs for research labs, especially those in middle- to low-income countries. In a previous work, our group developed "in house" electroporation buffers (termed "Chicabuffers") that had comparable efficiency with Lonza's buffers for the transfection of the human $\mathrm{T}$ cell line Jurkat and primary $\mathrm{T}$ lymphocytes from mouse and human origin (Chicaybam et al., 2013). Electroporation strategies using Chicabuffers were recently successfully applied to colon cancer cell lines (de Souza et al., 2013) and human mesenchymal stem cells (MSC; unpublished data). In the present work, we extend the efficiency analysis of Chicabuffers and the description of optimal electroporation conditions in a panel of cell lines and primary cells that represent relevant models for cell biology studies and disease comprehension. We selected 14 cell lines of mouse and human origin and primary human cells [MSC, peripheral blood mononuclear cells (PBMCs), and cord blood CD34+ cells], showing that these buffers yield high transfection efficiencies and are a viable option for genetic modification using the Nucleofector IIb electroporator. For cells in which the levels of transgene expression was low, we developed sleeping beauty (SB)-based transposon plasmids engineered to confer drug resistance, allowing fast and efficient drug-based selection of cells representing fractions of the cell culture.

We selected cells lines representing models for hematopoietic neoplasias (HEL, K562, P815, Nalm-6, and Jurkat cell lines) and different solid tumor-derived cell lines (A-549, B16-F10, HeLa, MCF-7, MDA-MB-231). Some of the tested cells represent classical cellular models for ectopic gene expression (293T, NIH-3T3), cell signaling (Jurkat and 293T), growth factor dependence (BA/F-3), or simply relevant cells in terms of therapy and cell differentiation (MSCs, PBMCs and Cord Blood CD34+ cells). In addition, we show that the level of transfection achieved using Chicabuffers allows efficient genomic edition of the potentially clinical relevant PD1 locus in human cells, such as 293T and PBMCs, using the recently described CRISPR/Cas9 system (Jinek et al., 2012).

\section{MATERIALS AND METHODS}

\section{Ethics Approval}

The use of PBMCs and CD34+ cells from healthy donors was approved by an IRB (Brazilian National Cancer InstituteINCA-Ethics Committee-protocol 153/13), and donors signed review board approved informed consents. MSCs were obtained from healthy donors submitted to surgery for hernia repair at the Clementino Fraga Filho University Hospital. The patients provided written informed consent, and the study was approved by the Hospital Research Ethics Committee.

\section{Plasmids and Cloning}

The pT3-GFP plasmid (Peng et al., 2009) was kindly provided by Dr. Richard Morgan (Surgery Branch-NCI). The pT2-GFP and SB100X (Mátés et al., 2009) constructs were kindly provided by Dr. Sang Wang Han (UNIFESP, Brazil). For the creation of pT3-Neo-EF1a-GFP plasmid, GFP was excised from pT3-GFP by digestion with AgeI/NotI, and the neomycin resistance gene (NEO), which was synthesized by Genscript (Piscataway, NJ, USA), was inserted. The EFla-GFP cassette was isolated from the plasmid pRRLsin.PPTs.EFla.GFPpre (Bonamino et al., 2004) (provided by Dr. Didier Trono, EPFL, Switzerland) after digestion with ClaI/BstBI and inserted in pT3-NEO previously digested with ClaI. For CRISPR experiments, the plasmid encoding $S$. pyogenes Cas9 (WT) and a U6 promoter for guide RNA (gRNA) expression was acquired from Addgene (pX330; \#42230). gRNA (CACCGGCCATCTCCCTGGCCCCCA) for programed cell death 1 (PDCD-1) was designed by Optimized CRISPR Design tool (http://crispr.mit.edu/) and cloned in pX330 (Addgene) using BbsI restriction site. pRGS-CR (Kim et al., 2011) was provided by Dr. Amilcar Tanuri (Federal University of 
Rio de Janeiro, Brazil), and PDCD1 target sequence cloned in EcoRI/BamHI sites, between a red fluorescent protein (RFP) and a GFP, resulting in an out-of-frame GFP. The GFP expression can be restored by CRISPR-mediated non-homologous end joining (NHEJ) repair. All plasmids were isolated using Qiamp Maxi prep kit from Qiagen (Germany) and quantified using a Nanodrop spectrophotometer. The new constructs described in this report are available at Addgene.

\section{Cell Lines and Primary Cells}

The origin and cell culture conditions for each cell line are described in Table S1 in Supplementary Material. The use of PBMCs from healthy donors was approved by an IRB (Brazilian National Cancer Institute-INCA-Ethics Committee), and donors signed review board approved informed consents. Within $24 \mathrm{~h}$ after blood collection, leukocytes were harvested by filtration and washed with phosphate buffered saline (PBS). A density gradient centrifugation using Ficoll-Hypaque ${ }^{\circledR}-1077$ was performed. Cells were centrifuged for $20 \mathrm{~min}$ at $890 \mathrm{~g}$ (slow acceleration/deceleration off), washed three times with PBS, and used for nucleofection. For CD34+ cells separation, mononuclear cells (MNCs) were isolated from umbilical cord blood after Ficoll density gradient using the same protocol above described. CD34+ cells were isolated from MNCs using CD34 MicroBead Kit (Miltenyi Biotech) following the manufacturer's instructions. The utilization of CD34+ cells was also approved by INCA's Ethics Committee.

Mesenchymal stem cells were isolated from abdominal subcutaneous adipose tissue fragments obtained from healthy donors submitted to surgery for hernia repair at the Clementino Fraga Filho University Hospital. The patients provided written informed consent, and the study was approved by the Hospital Research Ethics Committee. Fragments were cut into small pieces and incubated with $1 \mathrm{mg} / \mathrm{mL}$ collagenase type II (Sigma-Aldrich, MO, USA) under permanent shaking at $37^{\circ} \mathrm{C}$ for $30 \mathrm{~min}$. The cell suspension was centrifuged at $400 \mathrm{~g}$, room temperature, for $10 \mathrm{~min}$, and the pellet was resuspended on PBS, followed by filtration with $100-\mu \mathrm{m}$ mesh strainers. Cells were plated to expand MSCs at $3 \times 10^{4}$ cells $/ \mathrm{cm}^{2}$ density with low-glucose Dulbecco's modified Eagle's medium (DMEM Low-glucose, Gibco, CA, USA) supplemented with 10\% fetal bovine serum (Gibco, CA, USA) and $100 \mathrm{U} / \mathrm{ml}$ penicillin and $100 \mu \mathrm{g} / \mathrm{mL}$ streptomycin (Sigma-Aldrich, MO, USA). Cells were electroporated at passage 3 .

\section{Electroporation}

Generic cuvettes were used for all the electroporations (Mirus Biotech $^{\circledR}$, Madison, WI, USA cat.: MIR 50121). Cells were resuspended in $100 \mu \mathrm{l}$ of the desired buffer, and $4 \mu \mathrm{g}$ of the reporter plasmid (pT2-GFP transposon) were added. For long-term experiments, $1 \mu \mathrm{g}$ of SB100× was added. The seven different buffers tested in this work are described in Table S2 in Supplementary Material. Cells were transferred to a sterile $0.2-\mathrm{cm}$ cuvette and electroporated using the reported program (Table 1) of Lonza ${ }^{\circledR}$ Nucleofector $^{\circledR}$ II electroporation system. After transfection, cells were gently resuspended in $1 \mathrm{~mL}$ of pre-warmed RPMI medium supplemented only with $2 \mathrm{mM}$
L-Glutamine and 20\% FCS. All cells were seeded in 12-well plates and grown at $37^{\circ} \mathrm{C}$ and $5 \% \mathrm{CO}_{2}$. The medium was replaced by complete RPMI medium the following day, and cells were maintained as described previously.

\section{Electroporation Score Determination}

For non-adherent cell lines, viability determination was based on trypan blue exclusion and/or determination of the \% of cells displaying viable cell FSC vs. SSC parameters by flow cytometry analysis on cells negative after 7AAD staining. For adherent cells, viability determination was calculated based on the $\%$ of the OD obtained in Crystal Violet staining assays at $d+1$ or $\mathrm{d}+3$. Calculation was based on the formula $\%=100 \times[\mathrm{OD}$ for control (non-electroporated) cell line/(OD for control (nonelectroporated) cell line + OD for electroporated cell line)]. The "electroporation score" was calculated based on cell viability (after normalization against the viability of non-transfected cells) and transgene expression on $\mathrm{d}+1$, and the score set to the formula "Viability (\%)* Expression (\%)/F." A division factor ( $F=50$ for adherent cell lines and $F=100$ for non-adherent cell lines) was used in the score formula to fit the results in the graph scale.

\section{Crystal Violet Staining}

To assess viability of adherent cell lines, cells were plated in triplicate in 96-well microtiter plates immediately after electroporation. Cell viability was evaluated after $24 \mathrm{~h}$, and cell expansion was analyzed at day +1 by crystal violet. The crystal violet incorporation assay was performed by fixing the cells with ethanol for $10 \mathrm{~min}$, followed by staining them with $0.05 \%$ crystal violet in $20 \%$ ethanol for $10 \mathrm{~min}$ and solubilization with methanol as reported (Faget et al., 2012). The plate was read on a spectrophotometer at $595 \mathrm{~nm}$ (SpectraMax 190, Molecular Devices, Sunnyvale, CA, USA).

\section{In Vivo B16-F10 Tumor Model}

B16F10 cells were electroporated with $4 \mu \mathrm{g}$ of pT3-NEO-EF1aGFP and $1 \mu \mathrm{g}$ of SB100× in buffer $1 \mathrm{~S}$, program P-020 of Lonza Nucleofactor II. As negative controls, we electroporated cells only with pT3-NEO-EF1a-GFP. Each condition was plated in a 6-well plate. After reaching $80 \%$ confluence, G418 (Life Technologies) antibiotic was added at $2,000 \mu \mathrm{g} / \mathrm{mL}$. The medium was changed every 3 days and the antibiotic added. After selection with antibiotic or not, we injected $5 \times 10^{5}$ cells in the left flank of C57BL/ 6 mice. After 15 days, we excised the tumor and plated the cells in $25 \mathrm{~cm}^{2}$ culture flasks. After $24 \mathrm{~h}$, the culture medium was changed to eliminate non-adherent cells. After 3 days, the cells were recovered and analyzed by flow cytometry for GFP expression.

\section{CD34+ Differentiation Assay}

Electroporated CD34+ cells were assayed in two different concentrations, $5 \times 10^{2}$ and $2 \times 10^{3}$ cells/well. The cells were concentrated in $300 \mu \mathrm{L}$ and then added in $1.1 \times$ concentrated $3 \mathrm{~mL}$ Methocult ${ }^{\mathrm{TM}} \mathrm{H} 4034$ (Stem Cell Technologies Inc., Vancouver, BC, Canada), then seeded two wells of a six-well plates, $1.1 \mathrm{~mL} /$ well. Cells were cultivated for 3 weeks at $37^{\circ} \mathrm{C}$ in a humidified 
TABLE 1 | Summarized electroporation conditions for each cell line (based in Figure 2; d1 after electroporation).

\begin{tabular}{|c|c|c|c|c|c|c|c|}
\hline Cell line & Cell type & Program & $\begin{array}{l}\text { Recommended } \\
\text { buffer }\end{array}$ & $\begin{array}{c}\text { Viability } \\
\text { (Chicabuffer } \pm \text { SD) } \\
(\%)\end{array}$ & $\begin{array}{c}\text { Viability } \\
\text { (Lonza) } \\
(\%)\end{array}$ & $\begin{array}{c}\text { GFP } \\
\text { expression } \\
\text { (Chicabuffer) } \\
\text { (\%) }\end{array}$ & $\begin{array}{c}\text { GFP } \\
\text { expression } \\
\text { (Lonza) } \\
(\%)\end{array}$ \\
\hline \multicolumn{8}{|c|}{ Non-adherent } \\
\hline $\mathrm{BA} / \mathrm{F3}$ & Mouse pro B cell & $\mathrm{X}-001$ & $2 \mathrm{M}$ & $91.8 \pm 2.7$ & 79.00 & $55.05 \pm 14.2$ & 88.00 \\
\hline HEL & Erythroleukemia; erythroblast cell & X-005 & $1 S$ & $70.4 \pm 17.1$ & $39-66$ & $79 \pm 6.2$ & 94.00 \\
\hline Jurkat & Acute T cell leukemia, T lymphocyte; lymphoblastoid cells & X-001 & $1 \mathrm{SM}$ & $75.7 \pm 6.8$ & 90.00 & $69 \pm 11.6$ & 88.00 \\
\hline K562 & Human chronic myelogenous leukemia; lymphoblastoid cells & T016 & $1 \mathrm{M}$ & $70.7 \pm 13.8$ & 88.00 & $64.1 \pm 8$ & $80-90$ \\
\hline Nalm-6 & Human B cell precursor leukemia & C-005 & $3 \mathrm{P}$ & $74.2 \pm 11.8$ & 87.00 & $40.6 \pm 14.7$ & 64.00 \\
\hline P815 & Mouse mastocytoma; mast cells & C-005 & $3 P$ & $70.2 \pm 29.9$ & 92.00 & $60.5 \pm 16.6$ & 62.00 \\
\hline \multicolumn{8}{|l|}{ Adherent } \\
\hline A549 & Human lung carcinoma; epithelial cells & X-001 & $3 P$ & $59.4 \pm 27.3$ & 81.00 & $63.5 \pm 11.4$ & 72.00 \\
\hline 293Т & Human embryonal kidney; adherent fibroblastoid cells & A-023 & $1 \mathrm{SM}$ & $79.9 \pm 24.7$ & 90.00 & $38.6 \pm 30.2$ & 90.00 \\
\hline B16F10 & Mouse skin melanoma & P-020 & $2 S$ & $39.9 \pm 17$ & 91.00 & $49.3 \pm 15.7$ & 84.00 \\
\hline HeLa & Human cervix carcinoma; epitheloid cells in monolayers & $\mathrm{I}-013$ & $1 \mathrm{M}$ & $45.1 \pm 16.5$ & $85-90$ & $66.4 \pm 8.3$ & 70.00 \\
\hline MCF7 & Human breast adenocarcinoma; epithelial cells & P-020 & $1 \mathrm{M}$ & $68.4 \pm 10.9$ & 60.00 & $57 \pm 23.3$ & 77.00 \\
\hline $\begin{array}{l}\text { MDA- } \\
\text { MB-231 }\end{array}$ & Human breast adenocarcinoma; epithelial cells & $\mathrm{X}-013$ & $1 \mathrm{SM}$ & $85.6 \pm 15$ & 77.00 & $48.5 \pm 17.5$ & 79.00 \\
\hline $\begin{array}{l}\text { human } \\
\text { MSCs }\end{array}$ & Human mesenchymal stem cell & U-023 & $2 S$ & $58.5 \pm 6.8$ & 48.00 & $35 \pm 16.6$ & 80.00 \\
\hline NIH3T3 & NIH Swiss mouse embryo; adherent fibroblastoid cells & U-030 & $1 \mathrm{SM}$ & $49.4 \pm 30.4$ & 87.00 & $52.5 \pm 19.5$ & 84.00 \\
\hline
\end{tabular}

atmosphere supplemented 5\% $\mathrm{CO}_{2}$ in incubator 300/3000 Series (Revco, OH, USA). The colonies were identified and quantified using STEMvision ${ }^{\mathrm{TM}}$ (Stem Cell Technologies, Inc.) for the burst-forming units-erythroid, colony-forming units-erythroid, colony-forming units-granulocyte or macrophage or granulocytemacrophage, and colony-forming units-granulocyte/erythroid/ megakaryocyte/macrophage.

\section{Flow Cytometry}

FACSCalibur $^{\circledR}$ (BD Bioscience) was used to perform morphologic evaluation of viability (FSC vs. SSC) and GFP expression analysis. Cells were harvested the following days after transfection and resuspended in PBS at a concentration of $10^{5}$ cells $/ 500 \mu \mathrm{L}$. 7AAD staining (eBioscience cat. 00-6693) was performed immediately before FACS acquisition following manufacturer instructions. Data were analyzed using the FlowJo software (Tree Star). The hematopoietic progenitor CD34+ cells were evaluated for purity by staining with anti-CD34-PE (clone 581, BD Biosciences).

\section{CRISPR-Mediated Gene Editing}

HEK293FT and PBMCs were electroporated with pX330PDCD-1 $(10 \mu \mathrm{g})$ and pRGS-CR-target $(5 \mu \mathrm{g})$. Gene editions were evaluated by GFP+/RFP+ ratio after $24 \mathrm{~h}$ by flow cytometry. To characterize indels at PDCD1 locus, genomic DNA of gene edited cells was isolated by phenol-chloroform. Amplification of the target region was performed by PCR using the forward 5'-CCCCAGCAGAGACTTCTCAA and the reverse 5'-AGGACCGGCTCAGCTCAC primers. The PCR fragment was ligated in pCR2.1 vector (TA Cloning ${ }^{\circledR}$ Kit, Life Technologies), transformed in $\mathrm{DH} 5 \alpha$ cells and single bacteria colonies has the plasmid DNA extracted and sequenced using the primers described above.

\section{Short RNA and Plasmid Co-Electroporation}

After Ficoll gradient purification, PBMCs $\left(10^{7}\right.$ cells $)$ were electroporated with pRGS-CR-target $(10 \mu \mathrm{g})$ and $10-50 \mathrm{pmol}$ of FITC labeled RNA (Invitrogen) in Chicabuffer $3 \mathrm{P}$ and U-014 Nucleofector IIb program. Cells were left resting in $\mathrm{RPMI}+10 \% \mathrm{FCS}$ for $24 \mathrm{~h}$ at $37^{\circ} \mathrm{C}$ and $5 \% \mathrm{CO}_{2}$ and then evaluated by flow cytometry using ACCURI C6 (BD Bioscience).

\section{Statistical Analysis}

Data from electroporation experiments were analyzed by oneway ANOVA followed by Tukey's multiple comparison test using GraphPad Prism 6 software.

\section{RESULTS}

With the objective of determining the best-suited buffer for the electroporation of each cell line, cells were electroporated with seven different buffers and the viability and GFP expression were analyzed. Representative flow cytometry plots are depicted in Figure 1, showing 7AAD staining and GFP signal (gated in 7AAD negative cells) for a high electroporation score cell line (HEL) and FSC/SSC and GFP signal for a low score cell line (NIH3T3). $7 \mathrm{AAD}$ staining was performed only in the non-adherent cells since they represent a mixture of viable and non-viable cells at day 1 post electroporation. Adherent cells were allowed to adhere overnight after electroporation, and non-adherent/dead cells 


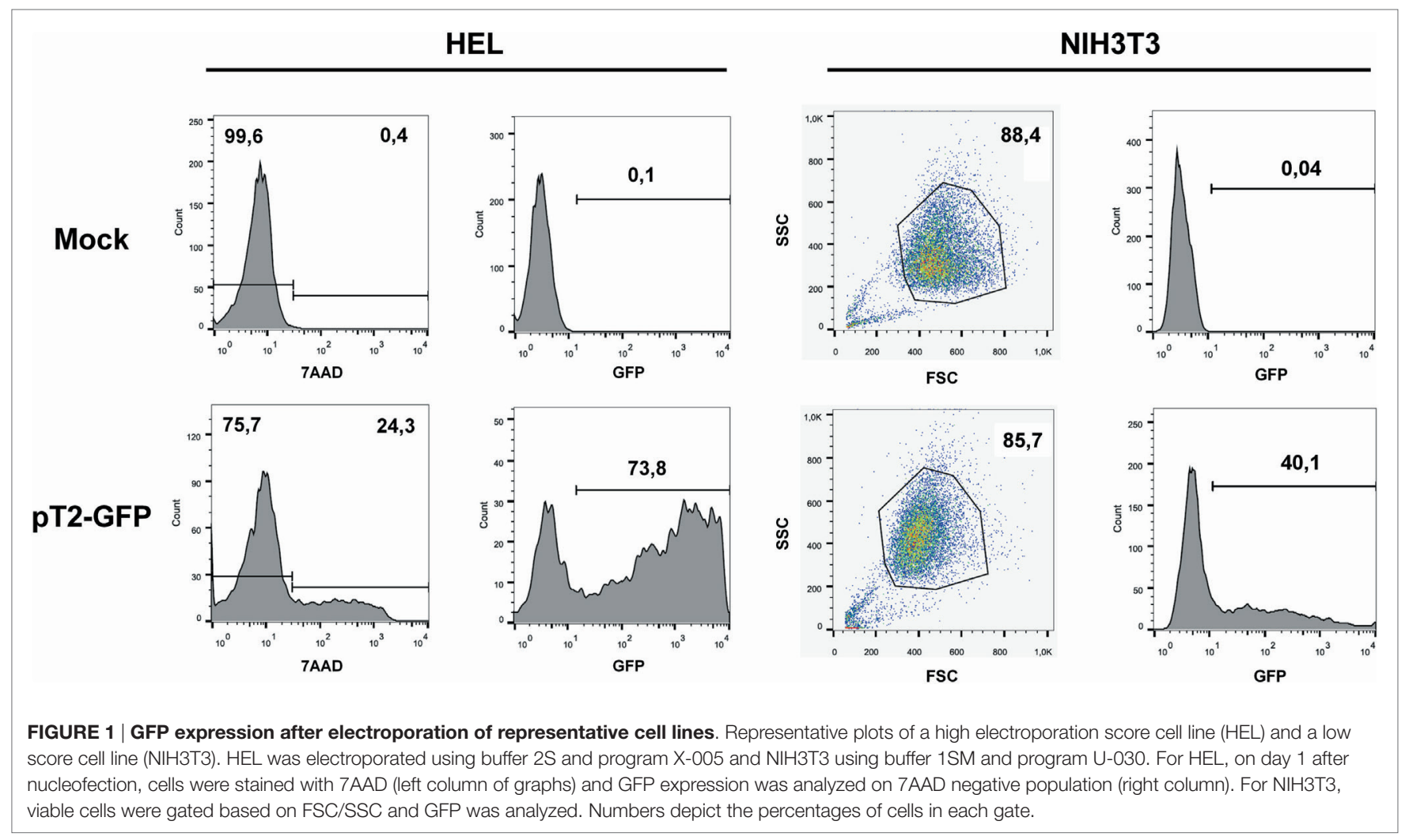

were discarded before FACS analysis. As showed in Figure 2, the majority of cell lines showed high electroporation scores independent of the buffer, with exception of P815, which showed an overall low efficiency but demonstrated best performance with buffer 3P. Suspension cell lines showed the best results regarding GFP expression, in which values above $60 \%$ were recurrently obtained. One exception is Nalm-6, with a maximum of $40 \%$ of GFP-positive cells obtained using buffer 3P. Adherent cell lines showed GFP values slightly lower (30-65\%), with Hela showing the best result with $66.4 \pm 8.3 \%$ of GFP expression using buffer 3P. Importantly, after $24 \mathrm{~h}$ of electroporation, the cells showed a good viability (Figure 2), allowing expansion and recovery from the nucleofection. Viability and GFP expression were followed for 10 days (suspension cell lines) or 7 days (adherent cell lines), with some cells retaining high levels of GFP (K562, HEL, B16F10) and others showing low expression of the marker after the expansion (NIH3T3, Jurkat, P815) (Figures S1-14 in Supplementary Material). These results probably reflect the observed differences in nucleofection efficiency and proliferation rates among the studied cells. The electroporation protocol for each cell line is summarized in Table 1.

Stable gene expression is often required in the experimental setting, allowing the generation of subclones with overexpression or silencing of a gene of interest. The emergence of nonviral vectors that allow the integration of transgenes, like the SB transposon system, simplified the genetic modification of cells, requiring only the delivery of two plasmids to achieve stable expression (one encoding the transgene flanked by ITRs-inverted terminal repeats-and one encoding the transposase). In order to evaluate if Chicabuffers could be used with this system, $1 \mu \mathrm{g}$ of SB100X (encoding a hyperactive version of the SB transposase) was electroporated with $4 \mu \mathrm{g}$ of pT2-GFP and GFP expression was followed for 30 days. As showed in Figure 3, the addition of SB100 $\times$ induced a higher percentage of GFP-positive cells after 30 days of culture when compared with control cells, strongly suggesting that integration of the transgene has occurred. This effect was more pronounced in B16F10, HeLa, and MCF7 cell lines, with approximately $20 \%$ of GFP-positive cells at day 30 . The other cell lines showed only a modest increase in GFP-positive cells at day 30 , ranging from $2 \%(\mathrm{BA} / \mathrm{F}-3)$ to $12 \%$ (K562). The long-term levels of GFP expression did not correlate with GFP expression at early days after nucleofection, suggesting that the cell lines have different intrinsic susceptibilities to SB-induced transgene integration.

For fast and easy enrichment of GFP-positive cells, we constructed a bidirectional vector encoding GFP and G418 resistance in the backbone of pT3 transposon, named pT3-Neo-EF1a-GFP. Indeed, the expression level obtained after nucleofection was sufficient to select G418-resistant clones after electroporation with this plasmid, as shown for NIH3T3 (Figure 4A) and B16F10 (Figure 4B) cell lines. After G418 selection and withdrawal, GFP expression remained stable in NIH3T3 cells for 15 days (Figure S15 in Supplementary Material). Furthermore, when the modified B16F10 cells were injected in vivo and allowed to form subcutaneous tumors, the cells extracted from the tumor at $d+14$ post inoculation (dpi) still expressed high levels of 

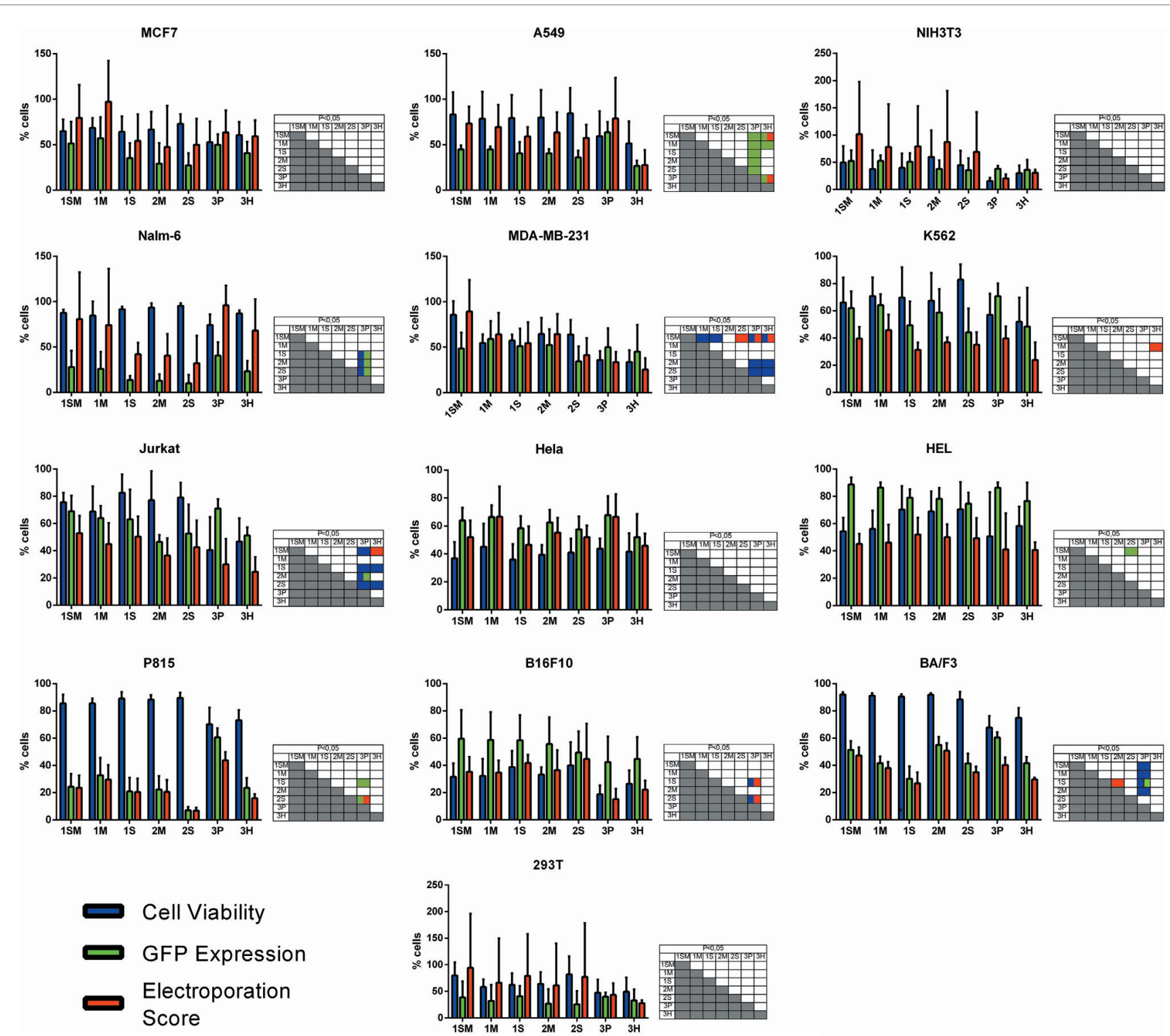

FIGURE 2 | Electroporation score for cell lines. Cell lines were electroporated with pT2-GFP (4 $\mu$ g) using each one of the seven buffers and the recommended program. Viability (blue bar), GFP expression (green bar), and electroporation score (red bar) were assessed 1 day after nucleofection ( $d+1$ ). Viability data were normalized with viability from non-transfected cells. Data are shown as mean \pm SD from three experiments performed in duplicate and were further analyzed using one-way ANOVA with Tukey's multiple comparisons test. Significant differences $(p<0.05)$ are depicted in the table next to each graph, with each color denoting one parameter.

GFP, indicating that the transgenic cassette is integrated in the genome and has stable expression, with no signs of in vivo silencing of the transgene (Figure 4C; Figure S16 in Supplementary Material).

Variations of the pT3-Neo-EF1a-GFP construct were developed, such as the pT3-Neo plasmid, which confers resistance to G418 antibiotic and has restriction sites that allow cloning of a second expression cassette. This plasmid was validated in G418 resistance assays using B16F10 cells (data not shown). The map for this plasmid is shown in Figure S18 in Supplementary Material.
The use of primary cells derived from patients or healthy donors provides a more accurate model for in vitro and in vivo experiments, and these cells can also be used in cell therapy approaches to treat a large number of diseases. However, these applications often depend on genetic modification, which is usually hard to perform in these cells. To evaluate the performance of Chicabuffers in the gene transfer to these cells, we isolated adipose tissue derived MSCs and cord blood purified CD34+ hematopoietic stem cells and electroporated the cells with the plasmids pT2-GFP and SB100×. As shown in Figure 5A, the best electroporation score for MSC was obtained using buffer 


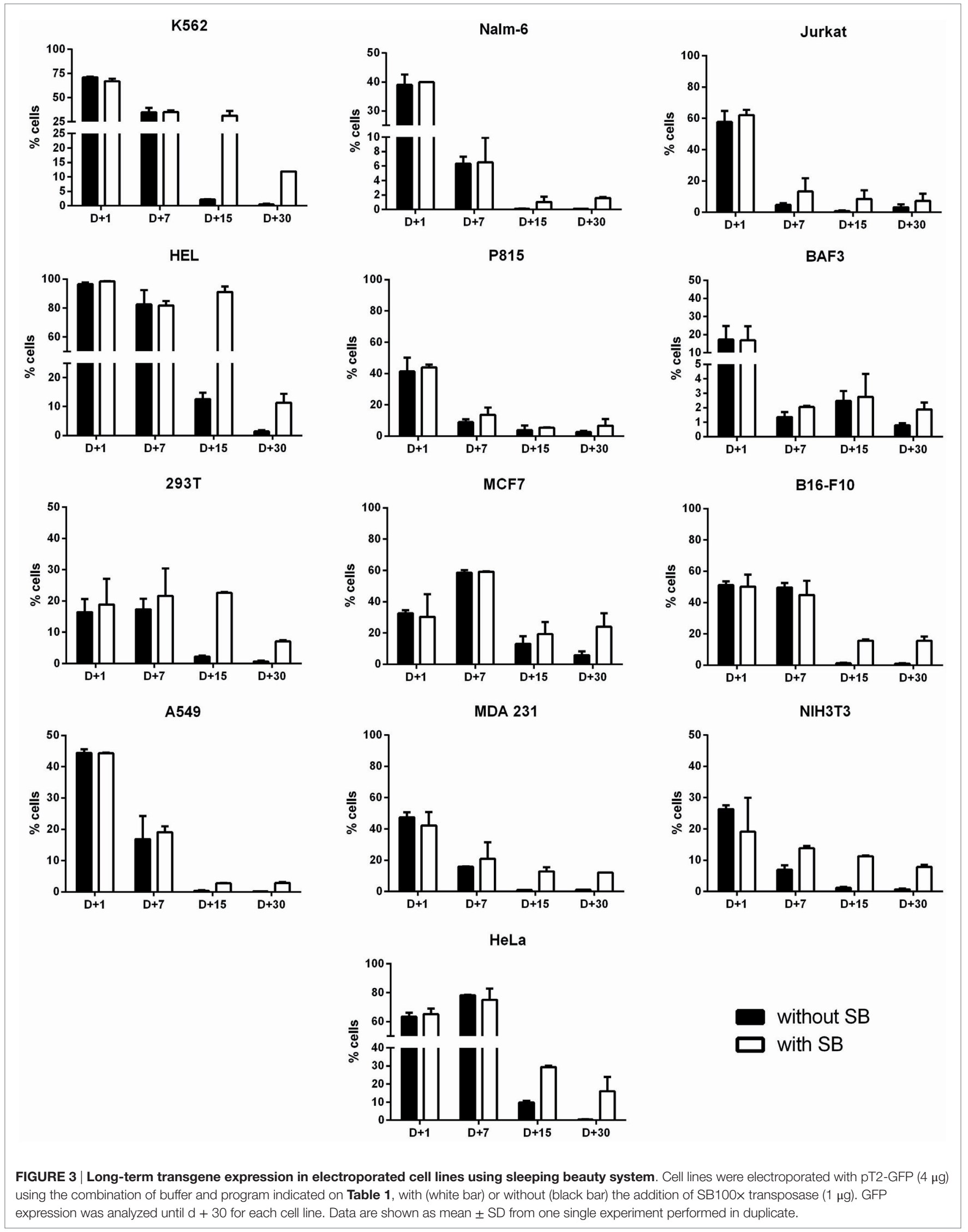




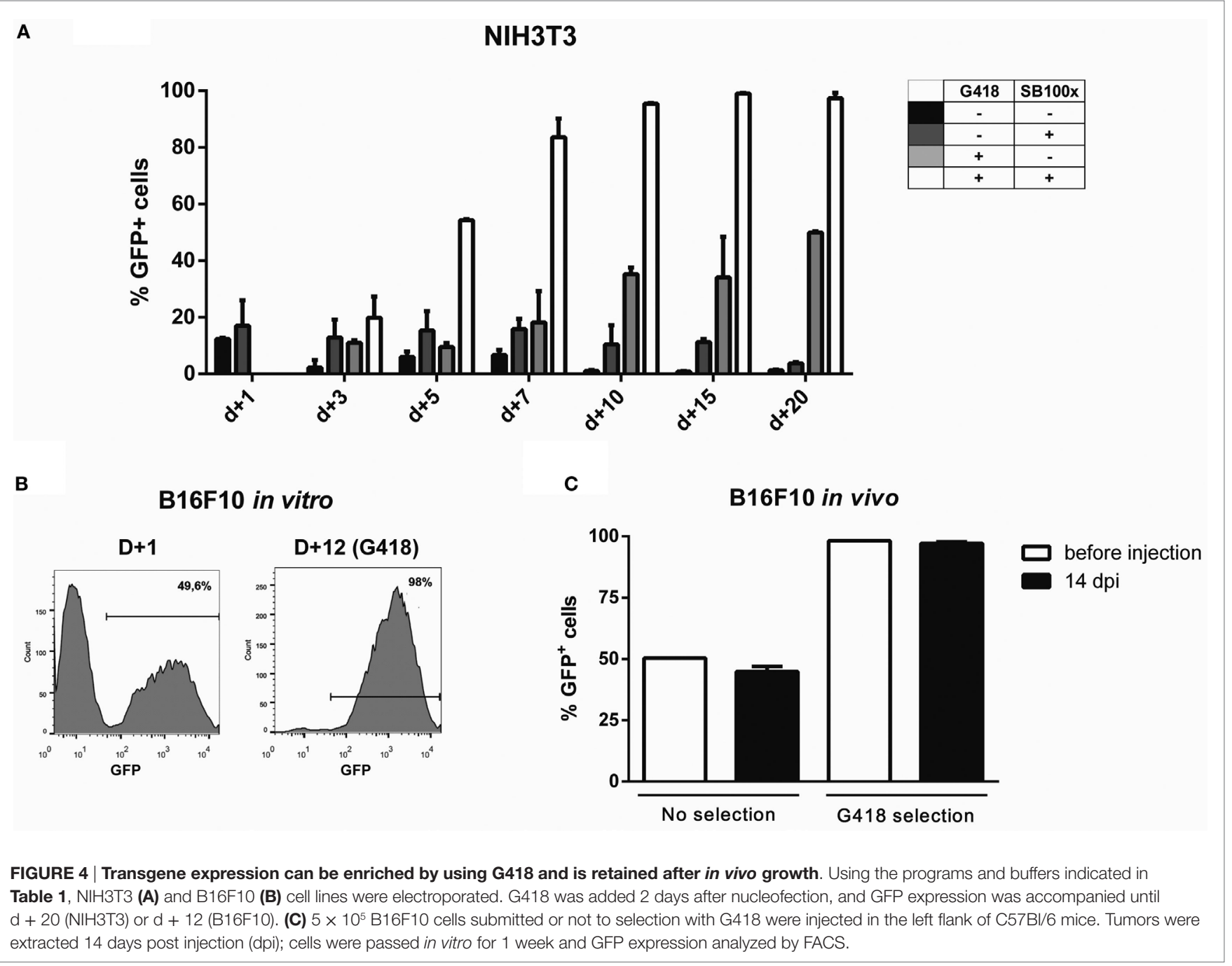

2 S, with $57 \%$ of viable cells and $39 \%$ of GFP expression. When using SB100 $\times$, long-term expression of GFP using this buffer was seen in $12 \%$ of cells (Figure 5B). For CD34 + cells, around 57\% were GFP-positive 1 day after electroporation using buffer $1 \mathrm{SM}$ and program U-008 (Figure 6A). These cells were plated in methylcellulose-based medium, allowing long-term assessment of GFP expression and differentiation potential. After 3 weeks, GFP+CD34+ cells were able to differentiate to erythroid, granulocytic, and myeloid lineages (Figure 6B), showing that the insertion of the transgene did not affect the stemness of the cells and that differentiated cells display high GFP expression (Figure S17 in Supplementary Mateiral).

The recent description of the CRISPR/Cas9 system as an efficient tool to edit the genome of cells has clear implications for basic cell biology studies and gene therapy protocols (Doudna and Charpentier, 2014). To achieve efficient gene editing of target cells, Cas9 nuclease and the gRNA must be expressed in the cell, ideally in a transient fashion. To evaluate the efficiency of Chicabuffers in promoting Cas9-mediated genome editing, we designed a gRNA targeting exon 2 of $P D C D 1$ gene, which encodes the inhibitory receptor PD-1, a relevant potential target for cancer cell-based immunotherapy (Hamid et al., 2013; Chicaybam and Bonamino, 2014). For the validation of gRNA, we used plasmid pRGS-CR-PDCD1, which has the PDCD1 target sequence cloned between a RFP and a GFP, resulting in an out-of-frame GFP. In this system, GFP expression can be restored by CRISPR-mediated NHEJ repair (Kim et al., 2011), leading to restoration of the reading frame in nearly $1 / 3$ of the editions. Co-electroporation of 293T cells with the report construct and the plasmid carrying CRISPR/Cas9/gRNA, but not CRISPR/Cas9 lacking the gRNA sequence, resulted in GFP expression in approximately $7 \%$ of the RFP+ cells (3\% out of $42 \%$ ), indicating that sequence-specific DNA editing was achieved (Figure 7A). A similar approach was performed in PBMCs and following electroporation, indels were verified by amplification of PDCD1 locus of the edited cells, which was subsequently cloned in pCR2.1 vector and analyzed by Sanger sequencing, evidencing cells containing indels of varying lengths in the PDCD1 locus (Figure 7B). The results of gene editing experiments in $293 \mathrm{~T}$ and PBMCs are summarized in 

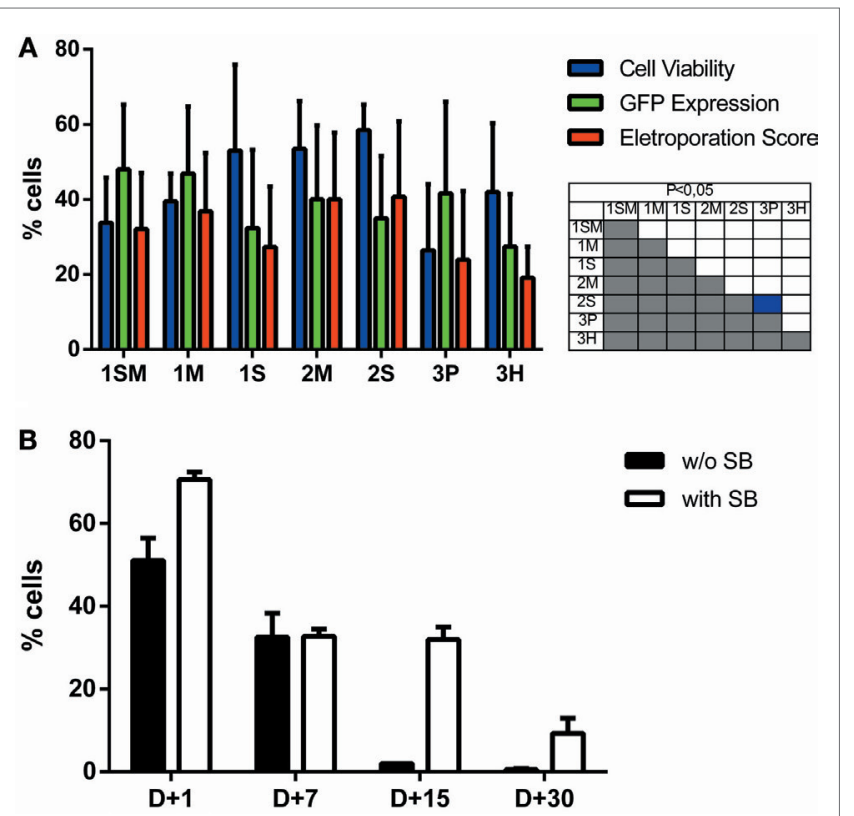

FIGURE 5 | Sleeping beauty-based GFP gene transfer to adipose tissue derived human mesenchymal stem cells (MSCs). (A) MSCs were electroporated with each one of the seven buffers and the recommended program. Viability (blue bar), GFP expression (green bar), and electroporation score (red bar) were assessed 1 day after nucleofection $(d+1)$. (B) Long-term GFP expression was evaluated until $d+30$ post nucleofection with (white bar) or without (black bar) the addition of SB100x transposase ( $1 \mu \mathrm{g}$ per cuvette). Data are shown as mean \pm SD from three experiments performed in duplicate and were further analyzed using one-way ANOVA with Tukey's multiple comparisons test. Significant differences $(p<0.05)$ are depicted in the table next to each graph, with each color denoting one parameter.

Figure 7C. The characterization of indels in PBMCs and 293T cells indicate that the use of our optimized electroporation protocol allowed efficient editing of PDCD1 locus in the tested samples. All the indels led to disruptions of the reading frame of the PD1 sequence (data not shown).

Multiple target editing is possible using CRISPR systems. Since multiple loci editing require multiple gRNA, we evaluated the possibility of co-electroporating PBMCs with a reporter plasmid and FITC labeled short RNAs. This setting could be used to coelectroporate a plasmid encoding a reporter gene (or Cas9 nuclease) and multiple short RNAs (such as gRNAs for editing several loci). Using the buffer 3P we were able to achieve high viability (Figure S19A in Supplementary Material) and up to $60.7 \%$ of cells expressing the short RNA when 50 pmol of the RNA were used (Figure S19B in Supplementary Material). Concentrations above 75 pmol of short RNA resulted in increased cell death and were not further used (data not show). From electroporated cells under the same condition, up to $14.8 \%$ co-expressed the reporter plasmid (encoding RFP) and the labeled short RNA (Figure S19C Supplementary Material). This setting clearly allows efficient coelectroporation of plasmid DNA and short RNA, opening the possibility of combining siRNA and transgene expression or even multiple gRNAs and Cas9 expressing plasmids for gene editing.

\section{DISCUSSION}

Genetic modification of cells is a cumbersome and expensive process, often involving the use of viral vectors to achieve high efficiency transgene expression. The use of electroporation for the genetic modification of cells is being adopted by many laboratories as it represents a fast and cheap option for transfer of plasmids and RNA. Moreover, this technique is also very efficient, inducing transgene expression levels comparable to viral vectors in some cells (Bilal et al., 2015). Equipments capable of generating square-wave voltage pulses, like Lonza Nucleofector, are among the most efficient for mammalian cell electroporation (Mir, 2014). However, costs associated with the acquisition of nucleofection kits, especially if used in a routine basis, might hamper the use of this technology in some laboratories or impair large-scale experiments.

In a previous work, our group described seven in house buffers and tested the electroporation efficiency of Jurkat cells and primary lymphocytes using Nucleofector (Chicaybam et al., 2013). The selected buffers induced high transgene expression and low toxicity, comparable to results obtained when Lonza's kit were used. In this context, the present work comprises a practical guide for the electroporation of 14 cell lines and primary MSCs and HSCs, determining the best buffer (among seven options) to be used with Lonza Nucleofector II, a widely disseminated electroporation device. The electroporation score calculated for every cell line is a general guide for electroporation efficiency comparison, and the buffer choice can be adapted to the need of the planned experiment (higher GFP expression or cell viability), allowing the researcher to experiment with different transgene expression levels. Chicabuffers showed to work for all the cells tested with most of the samples showing interchangeable results among the different buffers and only few exceptions where one of the buffers performed poorly or GFP expression was improved at the expense of cell viability, such as for buffer 3P in Jurkat cells. This illustrates that privileging GFP expression, for instance, can be detrimental to cell viability, opening room to further improvements in the electroporation protocol or buffer formulations. This results place Chicabuffers as a valuable tool for cheap and fast gene modification of basically every cell tested, with important potential applications in cell therapy and development and testing of synthetic circuits in mammalian cells. Although we focused in Lonza's device, it is likely that a similar approach using these buffers in conjunction with electroporators that allow modification of electroporation conditions could achieve even better results by fine tuning parameters like pulse amplitude, voltage, and wave forms (Yarmush et al., 2014). Lonza's buffers were already described to have good results when tested with alternative nucleofector IIb programs (Gresch et al., 2004), suggesting that there is still room for optimization of electroporation conditions, reinforcing the potential of testing Chicabuffers under different experimental settings.

Short-term viability and expression of GFP was very efficient for the majority of cell lines, and Chicabuffers performed equally well when compared to the results reported by Lonza, especially for non-adherent cell lines (Table 1 and Figure 2). Furthermore, 
A

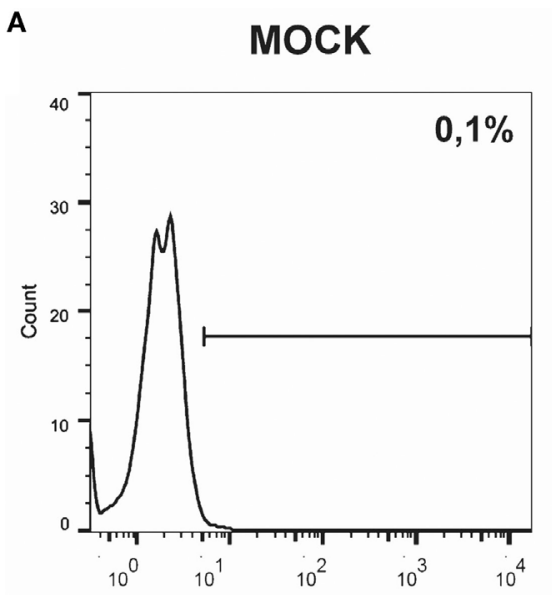

B

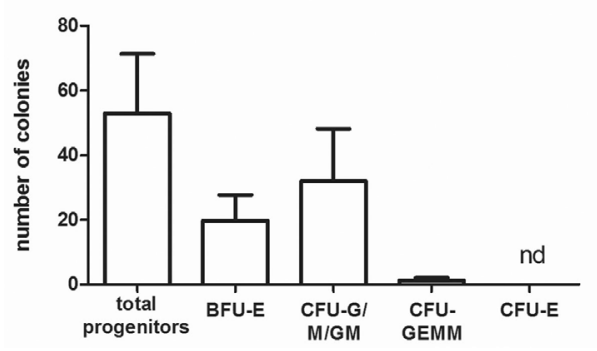

pT2-GFP (Buffer 1SM)

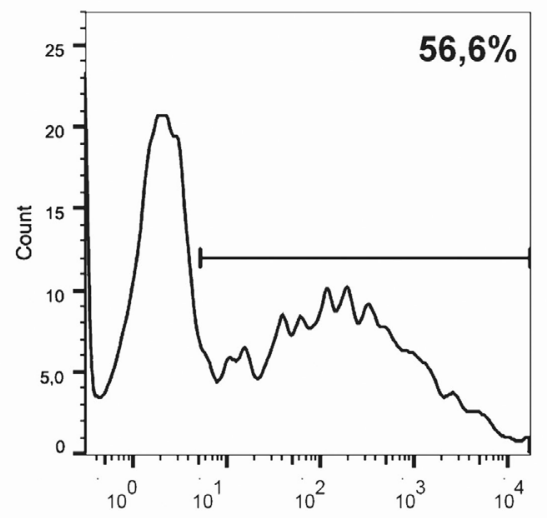

pT2-GFP

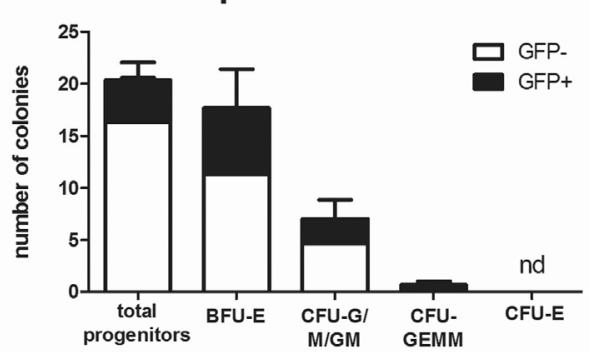

FIGURE 6 | Sleeping beauty-based GFP gene transfer to human cord blood CD34+ cells. (A) GFP expression in CD34+ cells electroporated with plasmids pT2-GFP $(4 \mu \mathrm{g})$ and SB100× $(1 \mu \mathrm{g})$ using program U-008 and buffer 1SM. GFP expression was evaluated by FACS at d + 1 post nucleofection. (B) Electroporated cells $\left(2 \times 10^{3}\right.$ per well) were plated in methylcellulose media and allowed to differentiate for 3 weeks. Colonies were quantified for mock (left) and GFP electroporated (right) cells. GFP-positive colonies (black bars) were determined within total colonies identified. CFU-E, colony-forming unit-erythroid; BFU-E, burst-forming unit-erythroid; CFU-G/M/GM, colony-forming unit-granulocyte/monocyte/; CFU-GEMM, colony-forming unit-granulocyte-erythrocyte-monocyte-megakaryocyte. Data are shown as mean \pm SD from two experiments.v

our results are comparable to those reported in the literature for cell lines like K562 (Gresch et al., 2004) and primary MSCs (Aluigi et al., 2006), although direct comparison of the results must be taken carefully because different plasmids were used. By combining this strategy with the SB transposon system, the provided optimized protocols allowed long-term expression of transgenes in all the cells tested (Figure 3). In the case of viral vectors, especially retroviral and lentiviral vectors, there is a wide availability of constructs carrying selectable markers, fluorescent reporters, promoters for different finalities, and cassette configurations, increasing the options of possible cellular manipulations (Szulc et al., 2006; Weber et al., 2008; Vargas et al., 2012). This is in sharp contrast to the SB system, which has a limited offer of transfer plasmids available. The new vectors developed and validated in the present report can improve flexibility and increase the applicability of this system, promoting accessible and efficient transgene integration into different cell types. These plasmids showed high and stable levels of transgene expression, and the addition of antibiotic resistance allowed the selection of GFP-expressing clones in vitro. Long-term expression of the transgene can be potentially increased by the use of SB100× RNA, decreasing the toxicity of the electroporation process as reported (Peng et al., 2009), or by carefully titrating the transposase plasmid mass to avoid overproduction inhibition (Grabundzija et al., 2010). These vectors and others recently reported in the literature (Kowarz et al., 2015), in conjunction with Chicabuffers, could be potentially used in diverse experimental gene therapy approaches, such as T cell immunotherapy (Singh et al., 2015), MSCs (Martin et al., 2014), and stem cell gene therapy protocols (Aiuti et al., 2013), further facilitating the application of these technologies in basic, translational, and clinical studies.

Our results show the feasibility of this approach, enabling a stable transgene expression in CD34+ cells from cord blood samples, keeping GFP expression throughout hematopoietic differentiation. It would be interesting to test this strategy in stem cell differentiation models other than the hematopoietic system such as the central nervous system (Sartore et al., 2011), including models of in vivo differentiation. In addition, cells with clear therapeutic potential, such as T lymphocytes (Chicaybam et al., 2013) and MSCs (this report) could be stably modified using a combination of Chicabuffer, SB, and electroporation.

Sleeping beauty-mediated modification of cells as described here proved to be stable in vitro and in vivo, with cells retaining transgene expression during tumor development in immunocompetent mice. The GFP+ B16F10 cells not only retained GFP 


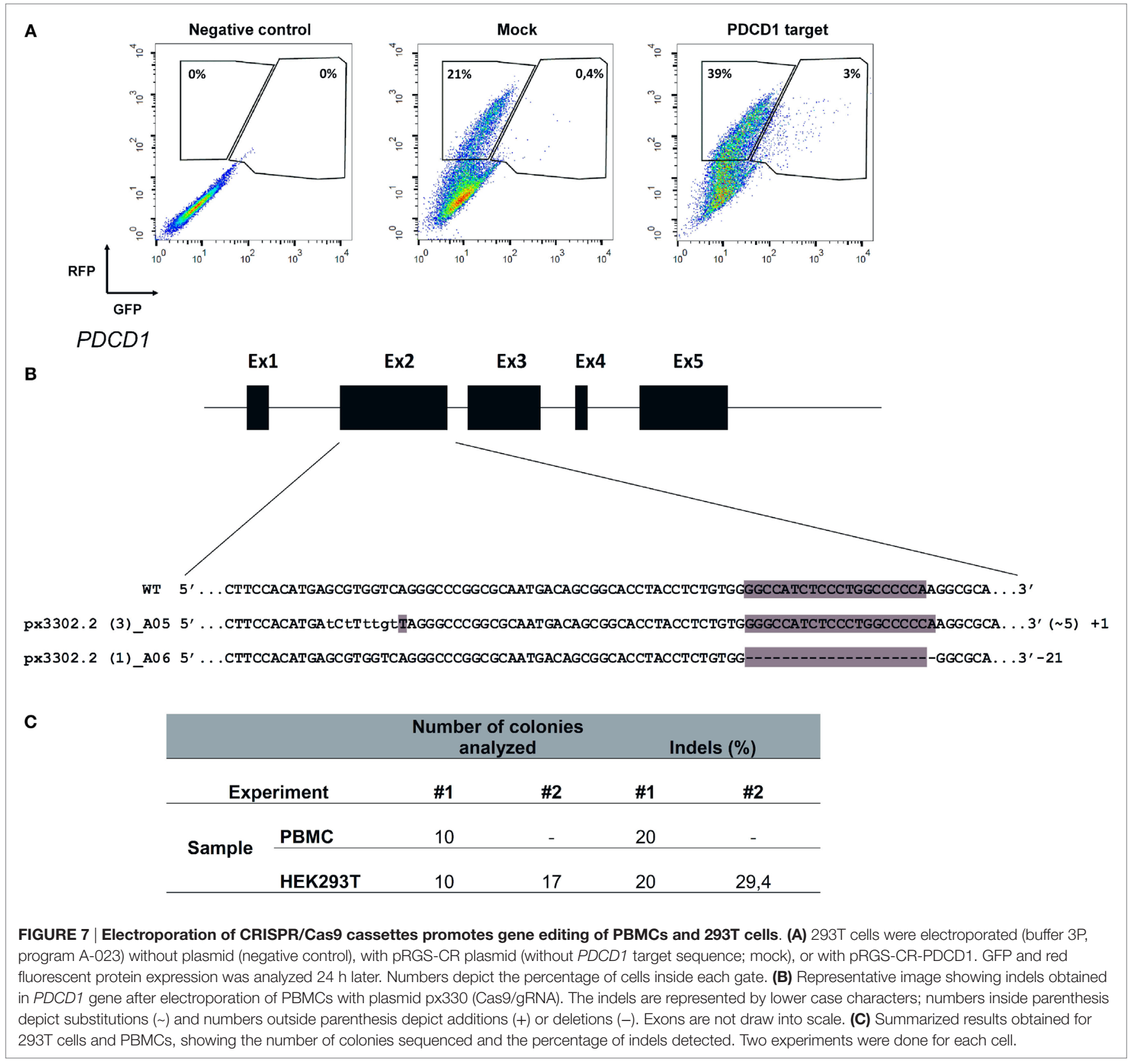

expression level, but also kept a constant ratio of GFP+/GFP-cells throughout the 15-day period of in vivo tumor development. This result suggests that no gene silencing occurs for the SB transgenic cassette, supporting in vivo utilization of this tool, as described elsewhere (Belur et al., 2003; Hausl et al., 2010).

Furthermore, we showed efficient CRISPR-mediated genome editing of PDCD1 gene in 293T and human PBMCs electroporated using Chicabuffers. Designing a single plasmid encoding Cas9+ gRNA is simpler than constructing zinc finger nuclease (Beane et al., 2015) or TALEN (Berdien et al., 2014)-based cassettes. The single plasmid approach for PBMC edition is also simpler to assemble than the recently reported Cas9+ gRNA ribonucleoproteins (Schumann et al., 2015), showing that our extremely simple protocol can be used to edit cell genomes. The gRNA used for PDCD1 locus edition in our report targets exon 2, in contrast to exon 1 editions promoted by Schumann et al. (2015), showing that different gRNAs can be used to efficiently disrupt the PDCD1 gene sequence. The levels of gene editing obtained with our approach allow similar downstream applications in primary lymphocytes as those proposed by the above mentioned reports, but with a reduced effort to design the gene editing tool (plasmid bases CRISPR system vs. TALEN or ZFN) or the electroporation reagents (plasmid vs. RNA + protein). Furthermore, the protocol described for the co-electroporation of short RNAs and plasmids carrying GFP+ Cas9 can be exploited for multiple loci editing in PBMCs, opening the possibility of targeting simultaneously 
several genes of interest. These results suggest that Chicabuffers can be used for CRISPR genome editing in different cell lines and primary cells, including large-scale screening of different gRNAs.

In summary, our study describes general guidelines for the efficient electroporation of primary mammalian cells and several cell lines. For cell lines not described in this study, Chicabuffers represent a good starting point for the optimization of electroporation protocol and facilitate the genetic modification of cell lines that are not frequently used. Furthermore, our data validate a series of flexible SB-based plasmids for the integration of transgenes and downstream selection of gene-modified cells. The combination of transposon, Chicabuffers, and electroporation, as described here, represents a straightforward approach for transient gene expression and permanent gene modification of cell lines and human primary cells.

\section{ETHICS STATEMENT}

The study was approved by the local Research Ethics Committees.

\section{AUTHOR CONTRIBUTIONS}

LC, $\mathrm{CB}, \mathrm{BP}, \mathrm{MC}, \mathrm{PR}$, and $\mathrm{LB}$ performed the electroporation experiments (cell lines, MSCs, and PBMCs) and data analysis and interpretation. CGL, CL, FP-B, and ZV performed electroporation and differentiation experiments in CD34+ cells and data analysis and interpretation. LC and MB took part in

\section{REFERENCES}

Aiuti, A., Biasco, L., Scaramuzza, S., Ferrua, F., Cicalese, M. P., Baricordi, C., et al. (2013). Lentiviral hematopoietic stem cell gene therapy in patients with Wiskott-Aldrich syndrome. Science 341, 1233151. doi:10.1126/science. 1233151

Aluigi, M., Fogli, M., Curti, A., Isidori, A., Gruppioni, E., Chiodoni, C., et al. (2006). Nucleofection is an efficient nonviral transfection technique for human bone marrow-derived mesenchymal stem cells. Stem Cells 24, 454-461. doi:10.1634/ stemcells.2005-0198

Barretina, J., Caponigro, G., Stransky, N., Venkatesan, K., Margolin, A. A., Kim, S., et al. (2012). The Cancer Cell Line Encyclopedia enables predictive modelling of anticancer drug sensitivity. Nature 483, 603-607. doi:10.1038/ nature 11003

Beane, J. D., Lee, G., Zheng, Z., Mendel, M., Abate-Daga, D., Bharathan, M., et al. (2015). Clinical Scale zinc finger nuclease-mediated gene editing of PD-1 in tumor infiltrating lymphocytes for the treatment of metastatic melanoma. Mol. Ther. 23, 1380-1390. doi:10.1038/mt.2015.71

Behr, J.-P. (2012). Synthetic gene transfer vectors II: back to the future. Acc. Chem. Res. 45, 980-984. doi:10.1021/ar200213g

Belur, L. R., Frandsen, J. L., Dupuy, A. J., Ingbar, D. H., Largaespada, D. A., Hackett, P. B., et al. (2003). Gene insertion and long-term expression in lung mediated by the sleeping beauty transposon system. Mol. Ther. 8, 501-507. doi:10.1016/ S1525-0016(03)00211-9

Berdien, B., Mock, U., Atanackovic, D., and Fehse, B. (2014). TALEN-mediated editing of endogenous $\mathrm{T}$-cell receptors facilitates efficient reprogramming of $\mathrm{T}$ lymphocytes by lentiviral gene transfer. Gene Ther. 21, 539-548. doi:10.1038/ gt.2014.26

Bilal, M. Y., Vacaflores, A., and Houtman, J. C. (2015). Optimization of methods for the genetic modification of human T cells. Immunol. Cell Biol. 93, 896-908. doi:10.1038/icb.2015.59

Blower, P. E., Verducci, J. S., Lin, S., Zhou, J., Chung, J.-H., Dai, Z., et al. (2007). MicroRNA expression profiles for the NCI-60 cancer cell panel. Mol. Cancer Ther. 6, 1483-1491. doi:10.1158/1535-7163.MCT-07-0009 the conception and design of the study, data interpretation, and manuscript writing. All the authors read and approved the final manuscript.

\section{ACKNOWLEDGMENTS}

The authors thank Sang Wang Han (UNIFESP-Brazil) for pT2GFP and SB100× plasmids, Richard Morgan (NIH) for pT3-GFP plasmid, and Amilcar Tanuri (UFRJ) for pRGS-CR plasmid. The authors also thank all the researchers who provided the cell lines used in this study.

\section{FUNDING}

This work was supported by grants from Conselho Nacional de Desenvolvimento Científico e Tecnológico (CNPq), Fundação de Amparo à Pesquisa do Estado do Rio de Janeiro (FAPERJ), Coordenação de Aperfeiçoamento de Pessoal de Nível Superior (CAPES), Brazilian National Cancer Institute (INCA), and Oncobiology program/Universidade Federal do Rio de Janeiro (UFRJ).

\section{SUPPLEMENTARY MATERIAL}

The Supplementary Material for this article can be found online at http://journal.frontiersin.org/article/10.3389/fbioe.2016.00099/ full\#supplementary-material.

Bonamino, M., Serafini, M., D’Amico, G., Gaipa, G., Todisco, E., Bernasconi, S., et al. (2004). Functional transfer of CD40L gene in human B-cell precursor ALL blasts by second-generation SIN lentivectors. Gene Ther. 11, 85-93. doi:10.1038/sj.gt.3302141

Chicaybam, L., and Bonamino, M. H. (2014). Moving receptor redirected adoptive cell therapy toward fine tuning of antitumor responses. Int. Rev. Immunol. 33, 402-416. doi:10.3109/08830185.2014.917412

Chicaybam, L., Sodre, A. L., Curzio, B. A., and Bonamino, M. H. (2013). An efficient low cost method for gene transfer to T lymphocytes. PLoS ONE 8:e60298. doi:10.1371/journal.pone.0060298

de Souza, W. F., Fortunato-Miranda, N., Robbs, B. K., de Araujo, W. M., de-Freitas-Junior, J. C., Bastos, L. G., et al. (2013). Claudin-3 overexpression increases the malignant potential of colorectal cancer cells: roles of ERK1/2 and PI3K-Akt as modulators of EGFR signaling. PLoS ONE 8:e74994. doi:10.1371/journal. pone.0074994

Doudna, J. A., and Charpentier, E. (2014). Genome editing. The new frontier of genome engineering with CRISPR-Cas9. Science 346, 1258096. doi:10.1126/ science. 1258096

Faget, D. V., Lucena, P. I., Robbs, B. K., and Viola, J. P. B. (2012). NFAT1 C-terminal domains are necessary but not sufficient for inducing cell death. PLoS ONE 7:e47868. doi:10.1371/journal.pone.0047868

Gillet, J.-P., Varma, S., and Gottesman, M. M. (2013). The clinical relevance of cancer cell lines. J. Natl. Cancer Inst. 105, 452-458. doi:10.1093/jnci/djt007

Grabundzija, I., Irgang, M., Mátés, L., Belay, E., Matrai, J., Gogol-Döring, A., et al. (2010). Comparative analysis of transposable element vector systems in human cells. Mol. Ther. 18, 1200-1209. doi:10.1038/mt.2010.47

Gresch, O., Engel, F. B., Nesic, D., Tran, T. T., England, H. M., Hickman, E. S., et al. (2004). New non-viral method for gene transfer into primary cells. Methods 33, 151-163. doi:10.1016/j.ymeth.2003.11.009

Griffin, J. L., and Shockcor, J. P. (2004). Metabolic profiles of cancer cells. Nat. Rev. Cancer 4, 551-561. doi:10.1038/nrc1390

Hamid, O., Robert, C., Daud, A., Hodi, F. S., Hwu, W.-J., Kefford, R., et al. (2013). Safety and tumor responses with lambrolizumab (Anti-PD-1) in melanoma. $N$. Engl. J. Med. 369, 134-144. doi:10.1056/NEJMoa1305133 
Hausl, M. A., Zhang, W., Müther, N., Rauschhuber, C., Franck, H. G., Merricks, E. P., et al. (2010). Hyperactive sleeping beauty transposase enables persistent phenotypic correction in mice and a canine model for hemophilia B. Mol. Ther. 18, 1896-1906. doi:10.1038/mt.2010.169

Jinek, M., Chylinski, K., Fonfara, I., Hauer, M., Doudna, J. A., and Charpentier, E. (2012). A programmable dual-RNA-guided DNA endonuclease in adaptive bacterial immunity. Science 337, 816-821. doi:10.1126/science.1225829

Jordan, M., and Wurm, F. (2004). Transfection of adherent and suspended cells by calcium phosphate. Methods 33, 136-143. doi:10.1016/j.ymeth.2003.11.011

Kim, H., and Kim, J.-S. (2014). A guide to genome engineering with programmable nucleases. Nat. Rev. Genet. 15, 321-334. doi:10.1038/nrg3686

Kim, H., Um, E., Cho, S.-R., Jung, C., Kim, H., and Kim, J.-S. (2011). Surrogate reporters for enrichment of cells with nuclease-induced mutations. Nat. Methods 8, 941-943. doi:10.1038/nmeth.1733

Kotnik, T., Frey, W., Sack, M., Haberl Meglič, S., Peterka, M., and Miklavčič, D. (2015). Electroporation-based applications in biotechnology. Trends Biotechnol. 33, 480-488. doi:10.1016/j.tibtech.2015.06.002

Kowarz, E., Löscher, D., and Marschalek, R. (2015). Optimized sleeping beauty transposons rapidly generate stable transgenic cell lines. Biotechnol. J. 10, 647-653. doi:10.1002/biot.201400821

Kuystermans, D., and Al-Rubeai, M. (2015). "Biopharmaceutical Products from Animal Cell Culture," in Animal Cell Culture Cell Engineering. Springer International Publishing, 717-757. doi:10.1007/978-3-319-10320-4_23

Martin, P. K., Stilhano, R. S., Samoto, V. Y., Takiya, C. M., Peres, G. B., da Silva Michelacci, Y. M., et al. (2014). Mesenchymal stem cells do not prevent antibody responses against human $\alpha$-L-iduronidase when used to treat mucopolysaccharidosis type I. PLoS ONE 9:e92420. doi:10.1371/journal.pone. 0092420

Mátés, L., Chuah, M. K. L., Belay, E., Jerchow, B., Manoj, N., Acosta-Sanchez, A., et al. (2009). Molecular evolution of a novel hyperactive sleeping beauty transposase enables robust stable gene transfer in vertebrates. Nat. Genet. 41, 753-761. doi:10.1038/ng.343

Mir, L. M. (2014). Electroporation-based gene therapy: recent evolution in the mechanism description and technology developments. Methods Mol. Biol. 1121, 3-23. doi:10.1007/978-1-4614-9632-8_1

Nishizuka, S., Charboneau, L., Young, L., Major, S., Reinhold, W. C., Waltham, M., et al. (2003). Proteomic profiling of the NCI-60 cancer cell lines using new high-density reverse-phase lysate microarrays. Proc. Natl. Acad. Sci. U.S.A. 100, 14229-14234. doi:10.1073/pnas.2331323100

Park, E. S., Rabinovsky, R., Carey, M., Hennessy, B. T., Agarwal, R., Liu, W., et al. (2010). Integrative analysis of proteomic signatures, mutations, and drug responsiveness in the NCI 60 cancer cell line set. Mol. Cancer Ther. 9, 257-267. doi:10.1158/1535-7163.MCT-09-0743

Peng, P. D., Cohen, C. J., Yang, S., Hsu, C., Jones, S., Zhao, Y., et al. (2009). Efficient nonviral sleeping beauty transposon-based TCR gene transfer to peripheral blood lymphocytes confers antigen-specific antitumor reactivity. Gene Ther. 16, 1042-1049. doi:10.1038/gt.2009.54

Ramanayake, S., Bilmon, I., Bishop, D., Dubosq, M.-C., Blyth, E., Clancy, L., et al. (2015). Low-cost generation of good manufacturing practice-grade CD19specific chimeric antigen receptor-expressing $\mathrm{T}$ cells using piggyBac gene transfer and patient-derived materials. Cytotherapy 17, 1251-1267. doi:10.1016/ j.jcyt.2015.05.013

Sartore, R. C., Campos, P. B., Trujillo, C. A., Ramalho, B. L., Negraes, P. D., Paulsen, B. S., et al. (2011). Retinoic acid-treated pluripotent stem cells undergoing neurogenesis present increased aneuploidy and micronuclei formation. PLoS ONE 6:e20667. doi:10.1371/journal.pone.0020667

Satkauskas, S., Ruzgys, P., and Venslauskas, M. S. (2012). Towards the mechanisms for efficient gene transfer into cells and tissues by means of cell electroporation. Expert Opin. Biol. Ther. 12, 275-286. doi:10.1517/14712598. 2012.654775

Schumann, K., Lin, S., Boyer, E., Simeonov, D. R., Subramaniam, M., Gate, R. E., et al. (2015). Generation of knock-in primary human T cells using Cas9 ribonucleoproteins. Proc. Natl. Acad. Sci. U.S.A. 112, 10437-10442. doi:10.1073/ pnas. 1512503112

Singh, H., Moyes, J. S. E., Huls, M. H., and Cooper, L. J. N. (2015). Manufacture of $\mathrm{T}$ cells using the sleeping beauty system to enforce expression of a CD19specific chimeric antigen receptor. Cancer Gene Ther. 22, 95-100. doi:10.1038/ cgt.2014.69

Szulc, J., Wiznerowicz, M., Sauvain, M.-O., Trono, D., and Aebischer, P. (2006). A versatile tool for conditional gene expression and knockdown. Nat. Methods 3, 109-116. doi:10.1038/nmeth846

Vargas, J. E., Salton, G., Sodré de Castro Laino, A., Pires, T. D., Bonamino, M., Lenz, G., et al. (2012). pLR: a lentiviral backbone series to stable transduction of bicistronic genes and exchange of promoters. Plasmid 68, 179-185. doi:10.1016/ j.plasmid.2012.06.001

Wang, T., Upponi, J. R., and Torchilin, V. P. (2012). Design of multifunctional non-viral gene vectors to overcome physiological barriers: dilemmas and strategies. Int. J. Pharm. 427, 3-20. doi:10.1016/j.ijpharm.2011.07.013

Weber, K., Bartsch, U., Stocking, C., and Fehse, B. (2008). A multicolor panel of novel lentiviral "gene ontology" (LeGO) vectors for functional gene analysis. Mol. Ther. 16, 698-706. doi:10.1038/mt.2008.6

Yarmush, M. L., Golberg, A., Serša, G., Kotnik, T., and Miklavčič, D. (2014). Electroporation-based technologies for medicine: principles, applications, and challenges. Annu. Rev. Biomed. Eng. 16, 295-320. doi:10.1146/ annurev-bioeng-071813-104622

Yin, H., Kanasty, R. L., Eltoukhy, A. A., Vegas, A. J., Dorkin, J. R., and Anderson, D. G. (2014). Non-viral vectors for gene-based therapy. Nat. Rev. Genet. 15, 541-555. doi: $10.1038 / \mathrm{nrg} 3763$

Conflict of Interest Statement: The authors declare that the research was conducted in the absence of any commercial or financial relationships that could be construed as a potential conflict of interest.

Copyright (c) 2017 Chicaybam, Barcelos, Peixoto, Carneiro, Limia, Redondo, Lira, Paraguassú-Braga, Vasconcelos, Barros and Bonamino. This is an open-access article distributed under the terms of the Creative Commons Attribution License (CC BY). The use, distribution or reproduction in other forums is permitted, provided the original author(s) or licensor are credited and that the original publication in this journal is cited, in accordance with accepted academic practice. No use, distribution or reproduction is permitted which does not comply with these terms. 